Supplementary Information for

\title{
Synthesis and Evaluation of Tetraarylethylene-based Mono-, Bis-, and Tris(pyridinium) Derivatives for Image-Guided Mitochondria-Specific Targeting and Cytotoxicity of Metastatic Melanoma Cells
}

Jessica L. Reedy ${ }^{\dagger}$, Devin K. Hedlund ${ }^{\dagger}$, Moustafa T. Gabr ${ }^{\dagger}$, Grant M. Henning ${ }^{\dagger}$, F. Christopher Pigge ${ }^{\ddagger}$, Michael K. Schultz ${ }^{\dagger *}$

${ }^{\dagger}$ Department of Radiology and Radiation Oncology, Free Radical and Radiation Biology Program, The University of Iowa, Iowa City, Iowa 52242, United States

Department of Chemistry, The University of Iowa, Iowa City, IA 52246, United States

\section{Contents}

FCCP Table of Values for JC-1 Assay

Table S1

${ }^{1} \mathrm{H}$ NMR spectrum of $\mathbf{2}$

$\mathrm{S} 2$

${ }^{13} \mathrm{C}$ NMR spectrum of 2

S3

${ }^{1} \mathrm{H}$ NMR spectrum of $\mathbf{4}$ S4

${ }^{13} \mathrm{C}$ NMR spectrum of 4 S5

${ }^{1} \mathrm{H}$ NMR spectrum of $\mathbf{6}$

${ }^{13} \mathrm{C}$ NMR spectrum of $\mathbf{6}$

${ }^{1} \mathrm{H}$ NMR spectrum of 8

${ }^{13} \mathrm{C}$ NMR spectrum of $\mathbf{8}$

${ }^{1} \mathrm{H}$ NMR spectrum of 9

${ }^{13} \mathrm{C}$ NMR spectrum of 9

UV-vis absorption spectrum of $2(\mathrm{MeCN}, 10 \mu \mathrm{M})$

$\mathrm{UV}$-vis absorption spectrum of $2(\mathrm{MeOH}, 10 \mu \mathrm{M})$

UV-vis absorption spectrum of $4(\mathrm{MeCN}, 10 \mu \mathrm{M})$

UV-vis absorption spectrum of $4(\mathrm{MeOH}, 10 \mu \mathrm{M})$

UV-vis absorption spectrum of $6(\mathrm{MeCN}, 10 \mu \mathrm{M})$

UV-vis absorption spectrum of $6(\mathrm{MeOH}, 10 \mu \mathrm{M})$

UV-vis absorption spectrum of $9(\mathrm{MeCN}, 10 \mu \mathrm{M})$

UV-vis absorption spectrum of $9(\mathrm{MeOH}, 10 \mu \mathrm{M})$

Fluorescence emission spectra of $\mathbf{2}$ in $\mathrm{MeCN}$ and $\mathrm{MeOH}$

Fluorescence emission spectra of $\mathbf{4}$ in $\mathrm{MeCN}$ and $\mathrm{MeOH}$

Fluorescence emission spectra of $\mathbf{6}$ in $\mathrm{MeCN}$ and $\mathrm{MeOH}$

Fluorescence emission spectra of 9 in $\mathrm{MeCN}$ and $\mathrm{MeOH}$ 
Figure S2

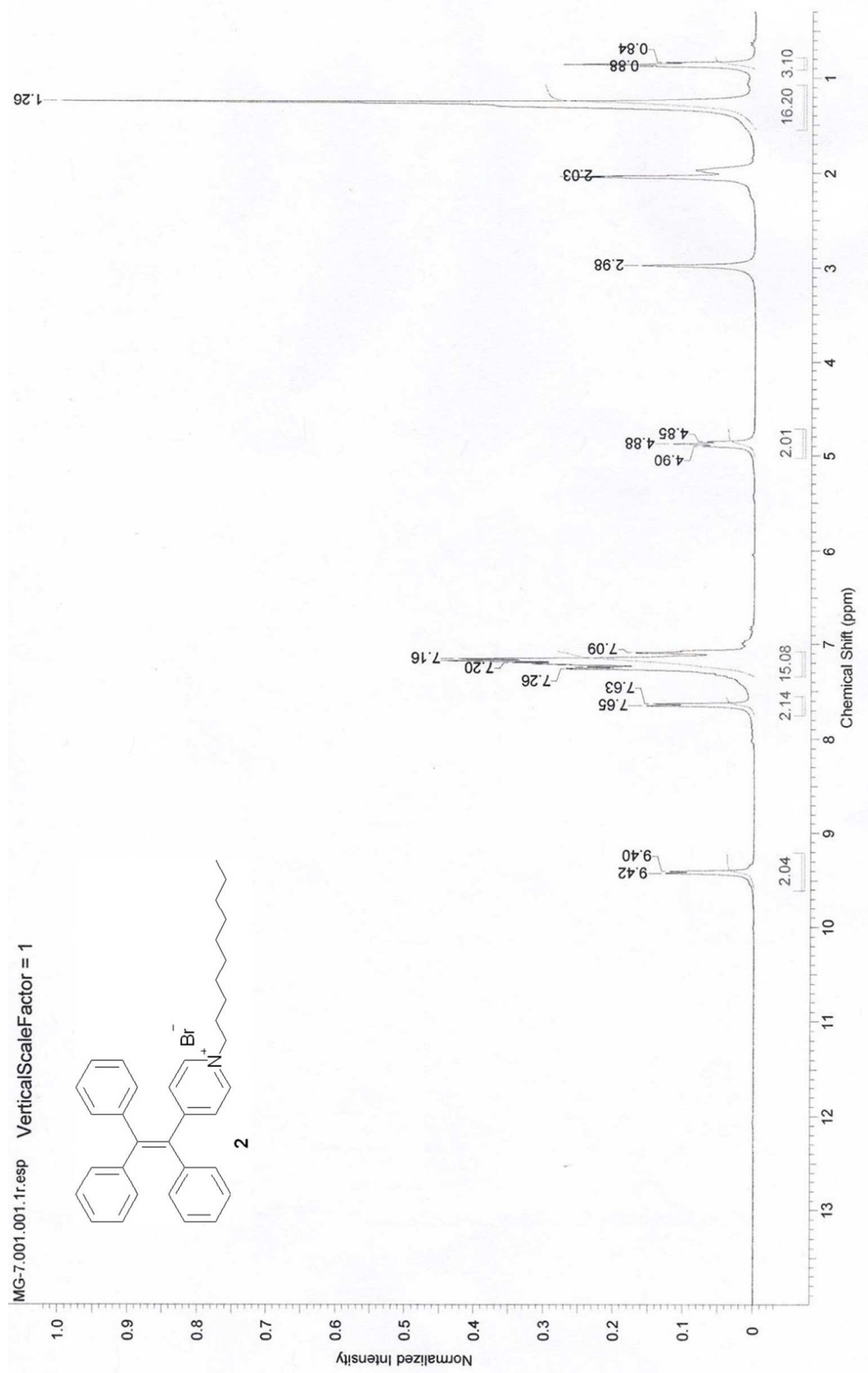


Figure S3

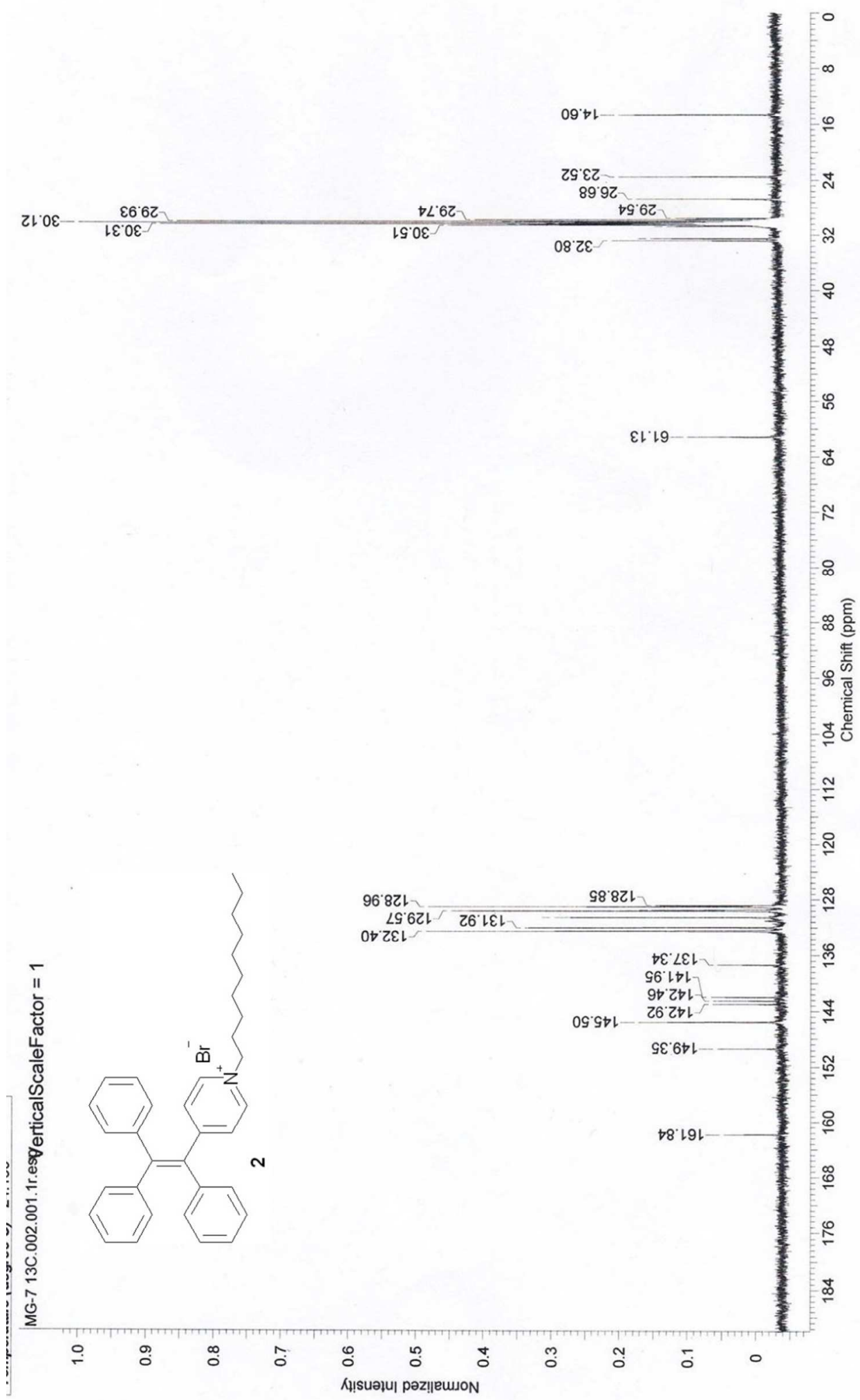

Page 3 of 16 
Figure S4

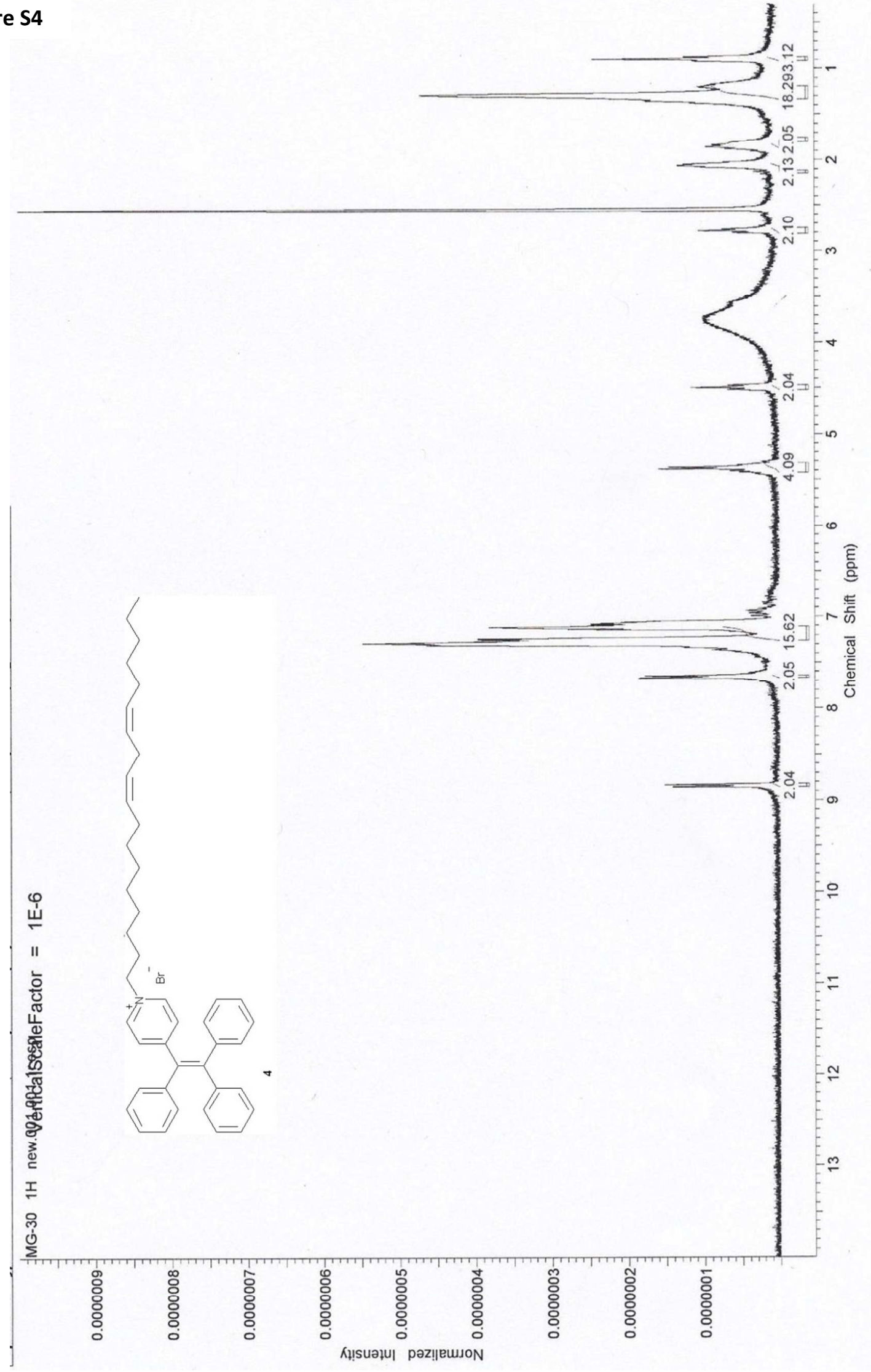


Figure S5

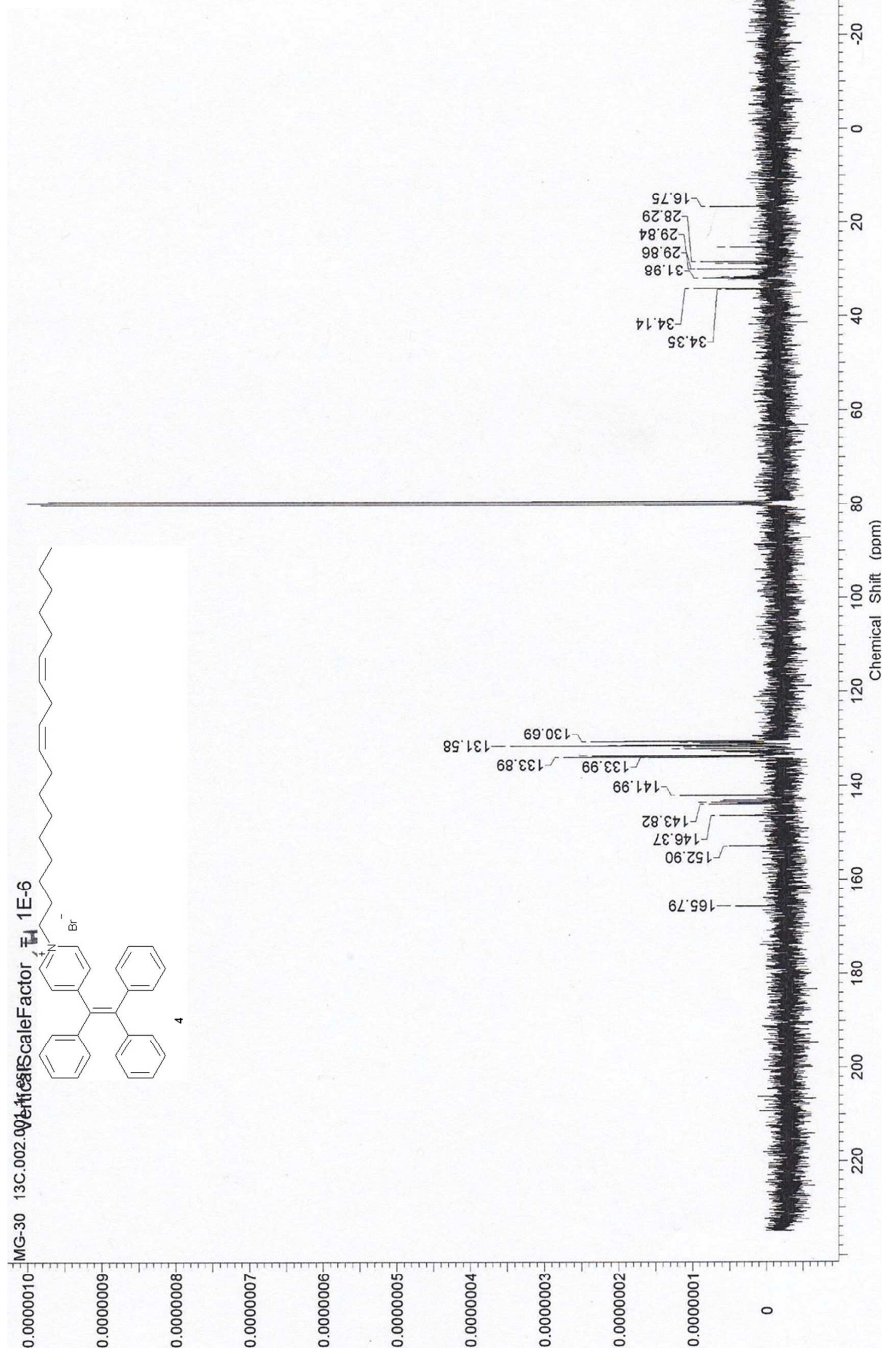


Figure S6

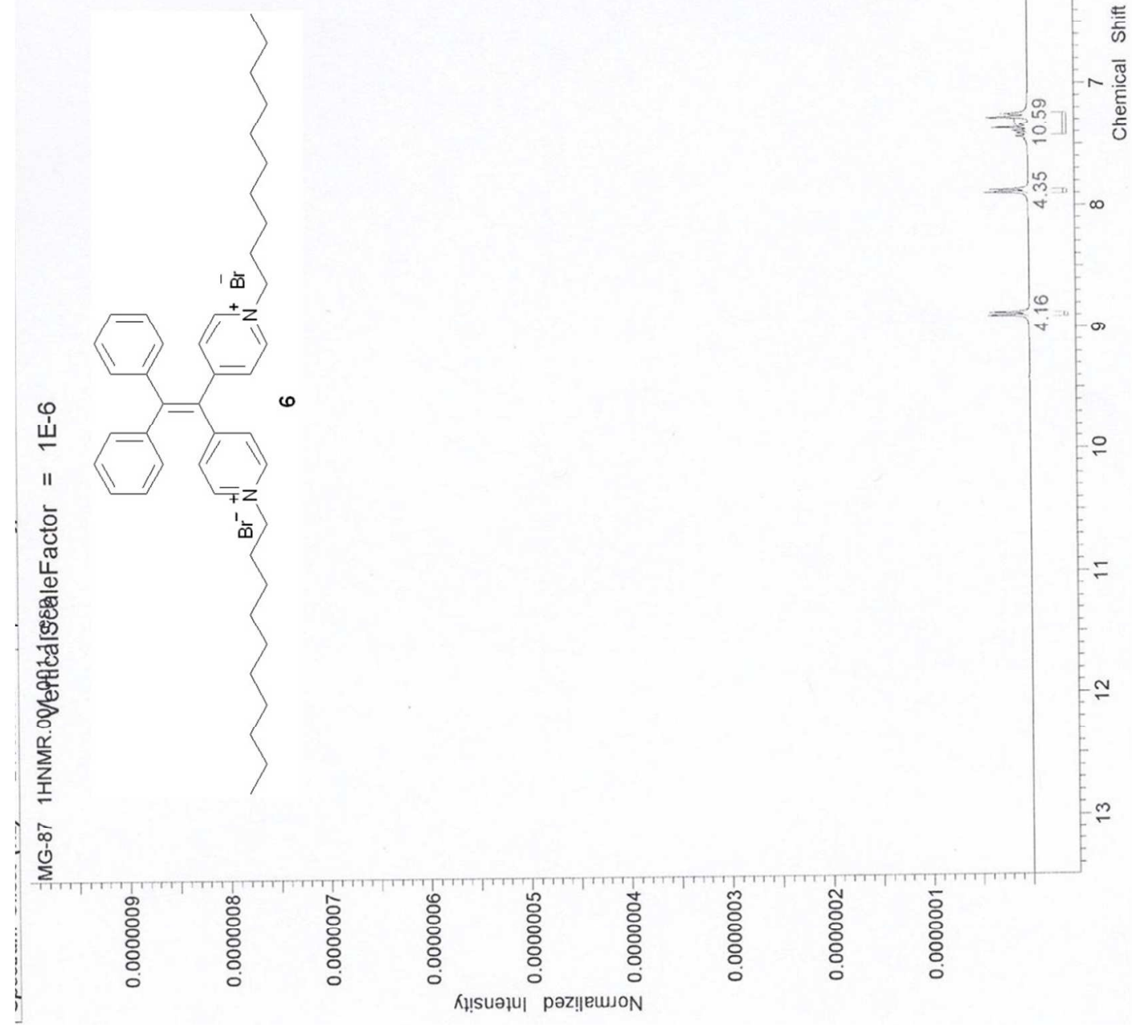




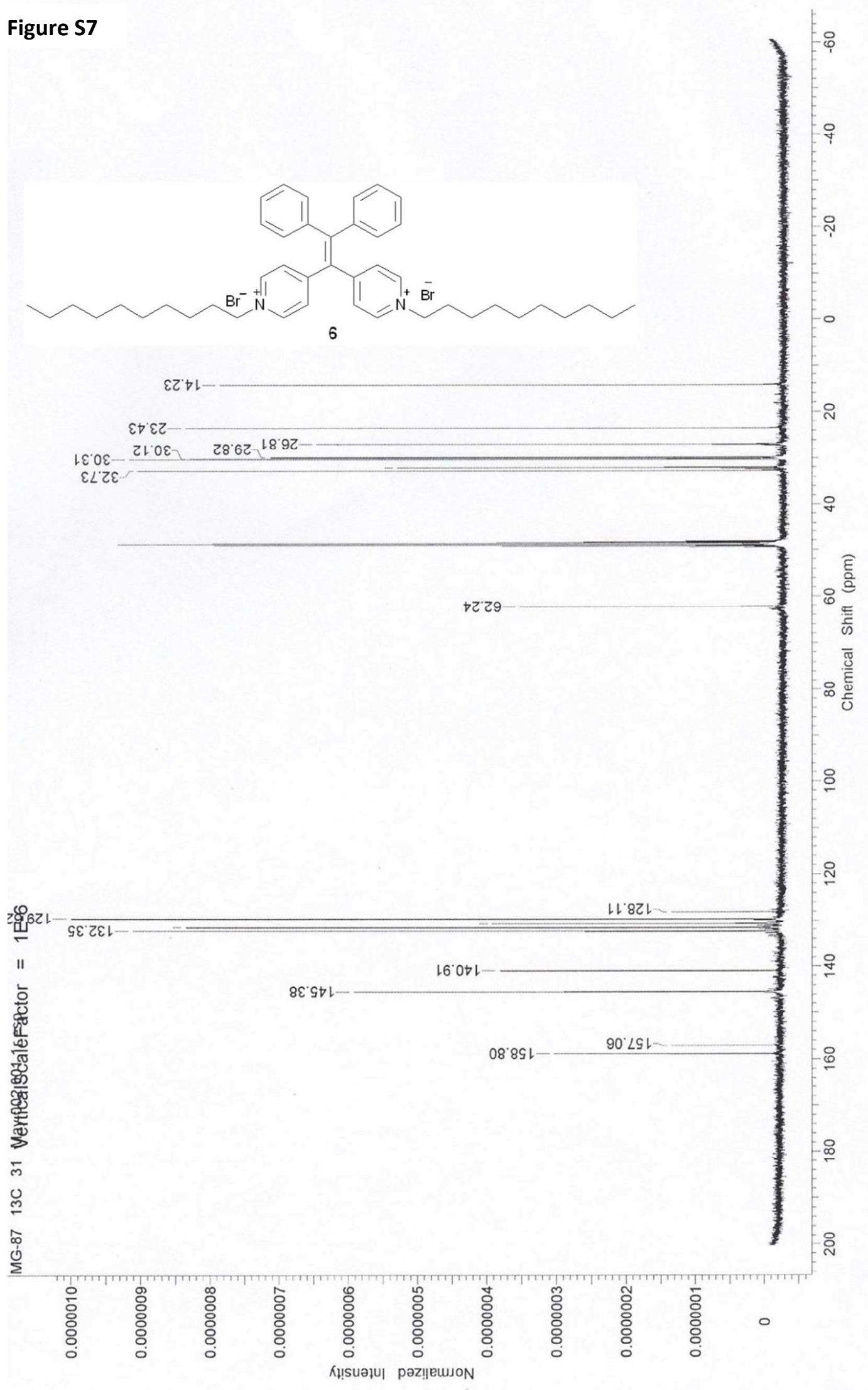

Page 7 of 16 
Figure S8

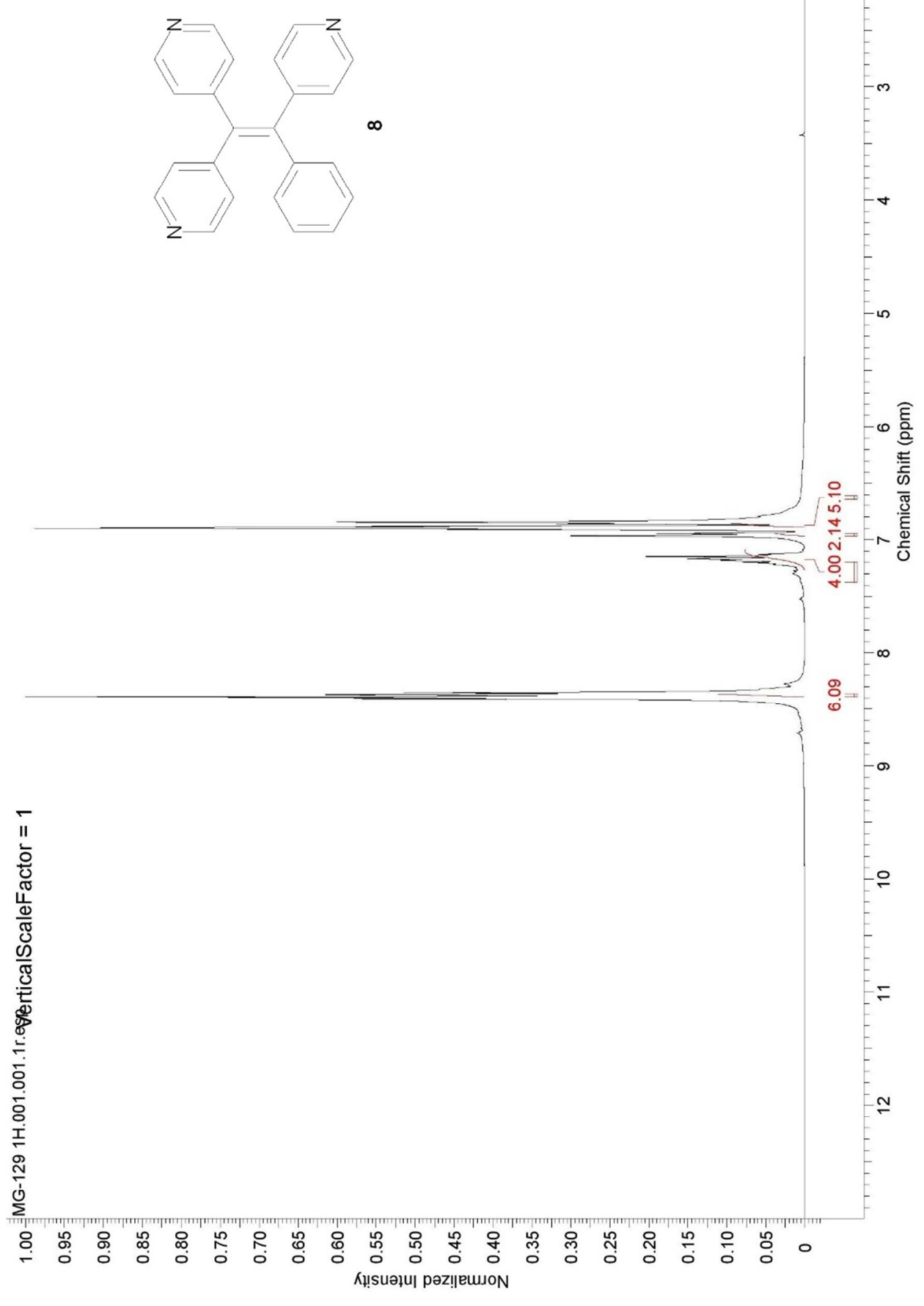

Page 8 of 16 
Figure S9

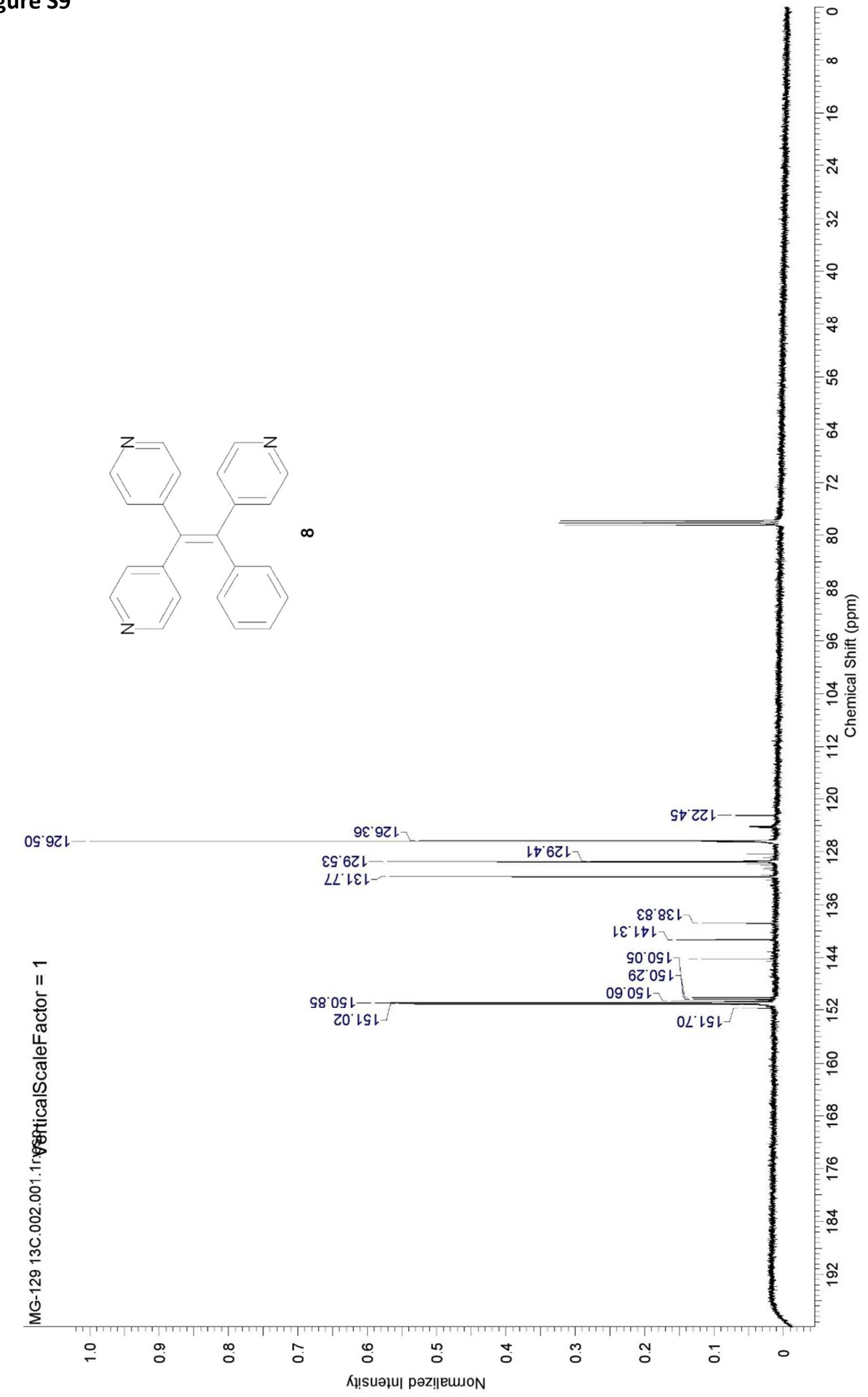

Page 9 of 16 
Figure S10

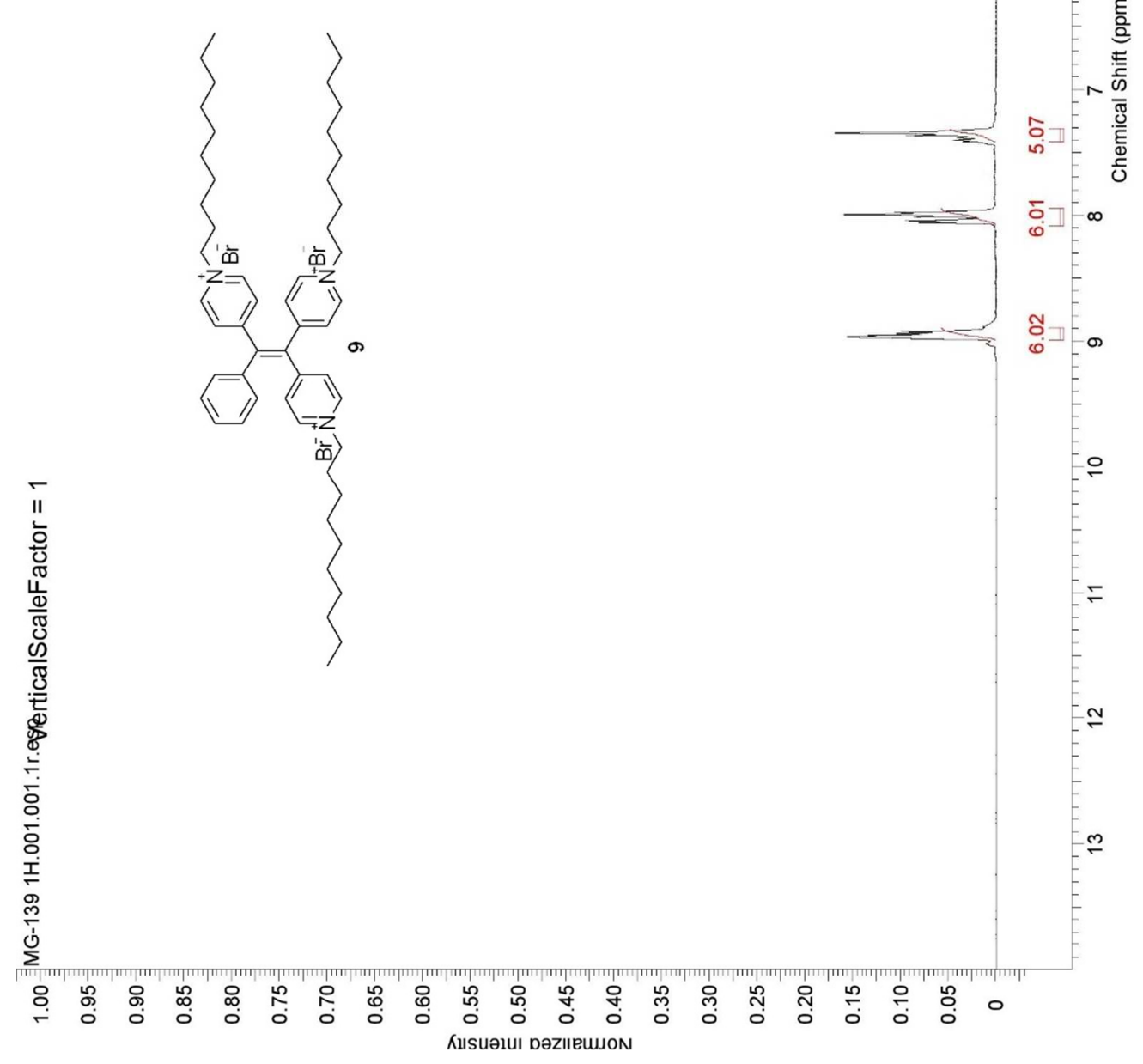


Figure S11

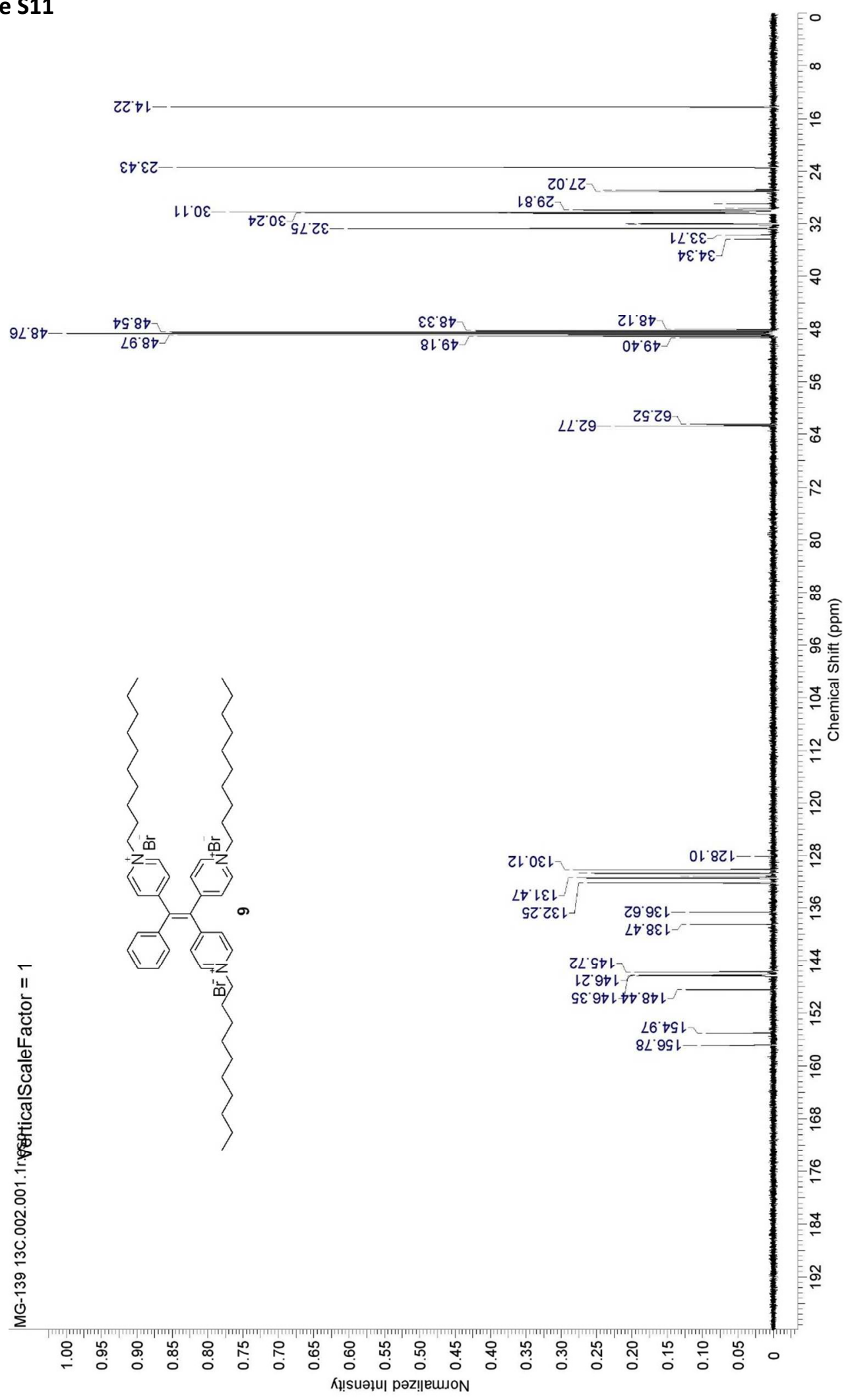

Page 11 of 16 


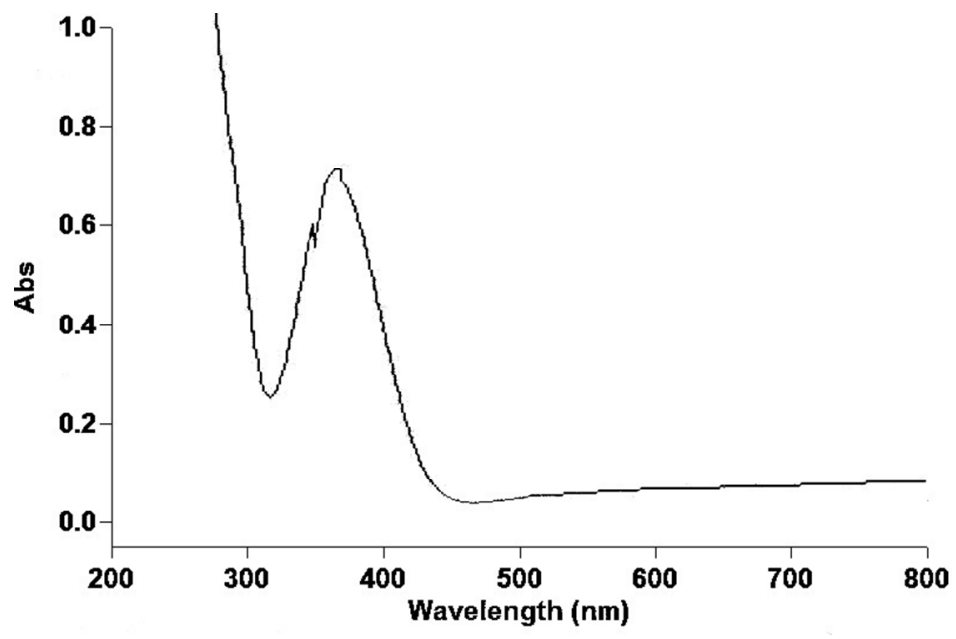

Figure S11. UV-vis absorption spectrum of 2 (MeCN, $10 \mu \mathrm{M})$.

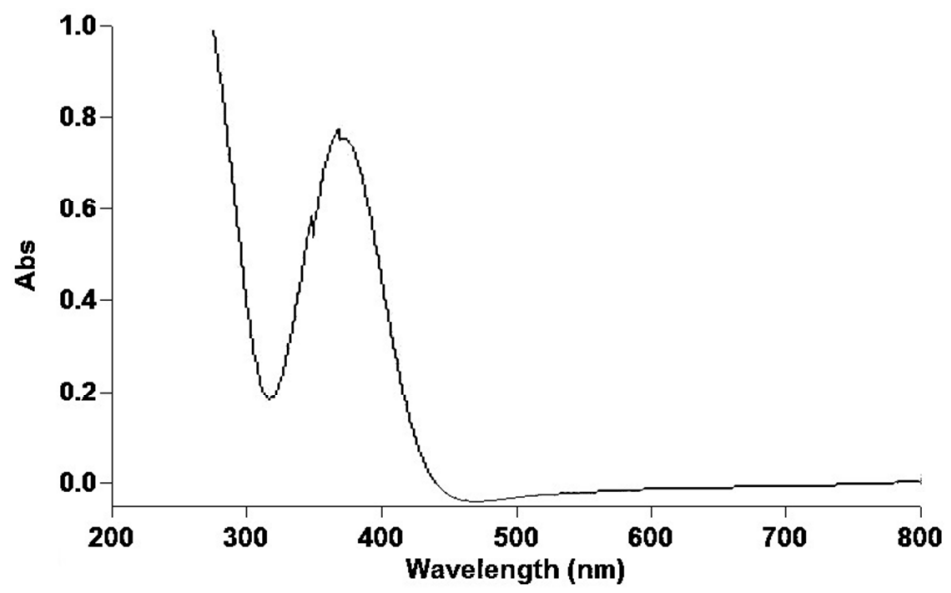

Figure S12. UV-vis absorption spectrum of $2(\mathrm{MeOH}, 10 \mu \mathrm{M})$.

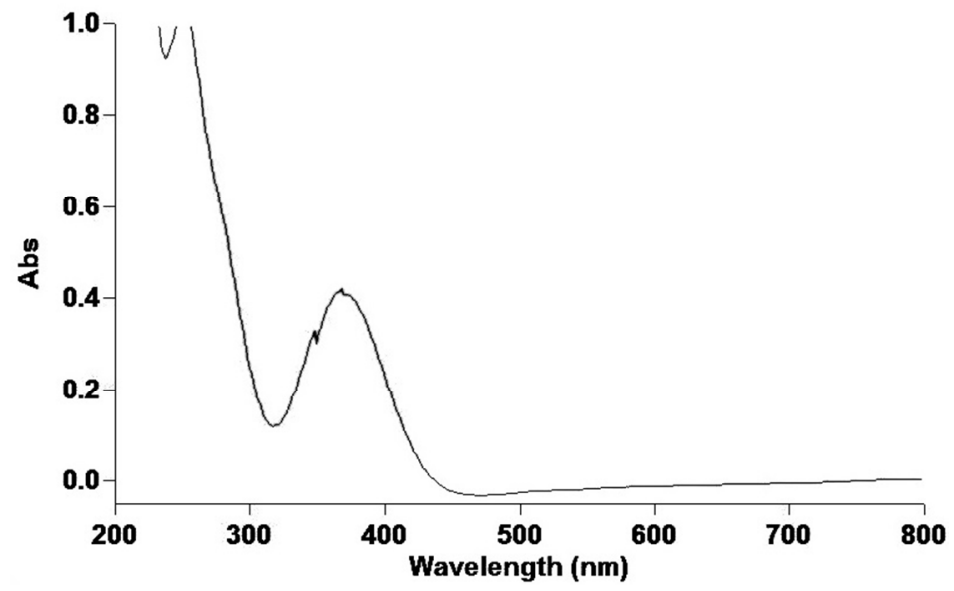

Figure S13. UV-vis absorption spectrum of 4 ( $\mathrm{MeCN}, 10 \mu \mathrm{M})$. 


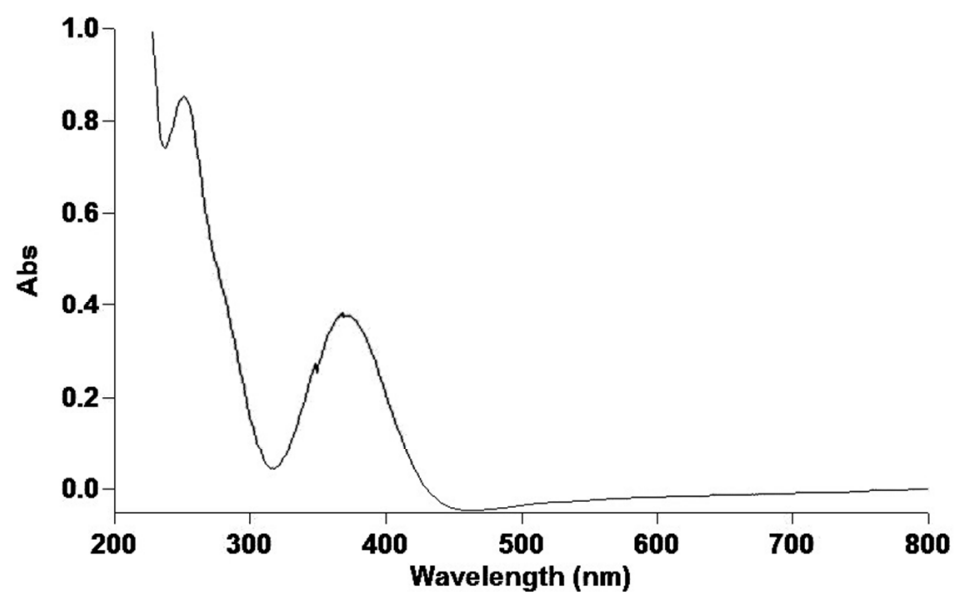

Figure S14. UV-vis absorption spectrum of $4(\mathrm{MeOH}, 10 \mu \mathrm{M})$.

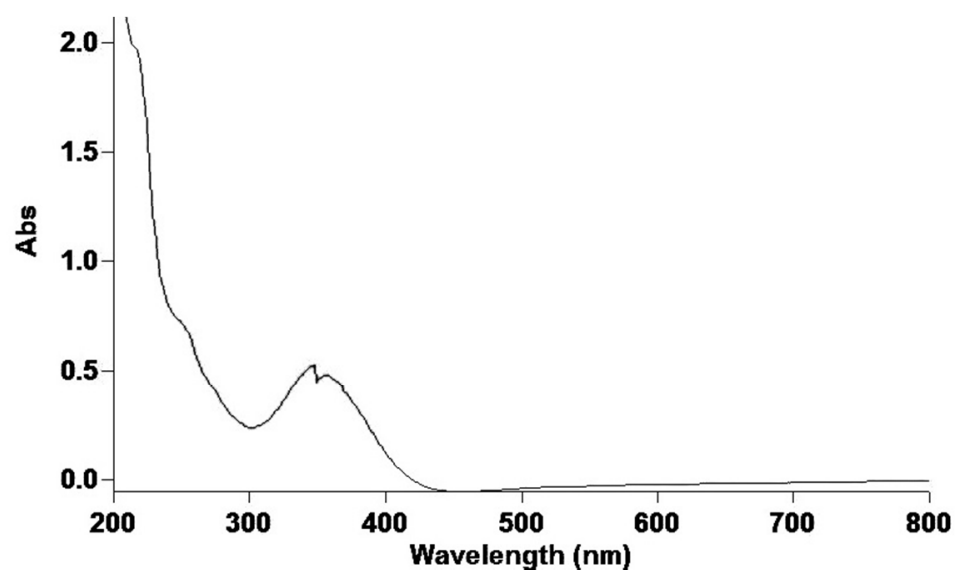

Figure S15. UV-vis absorption spectrum of 6 (MeCN, $10 \mu \mathrm{M})$.

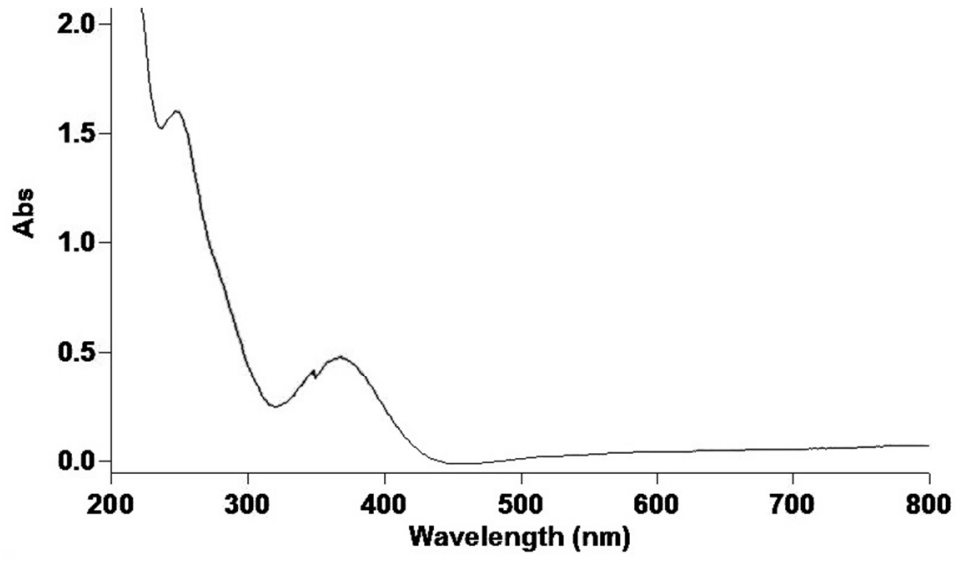

Figure S16. UV-vis absorption spectrum of $6(\mathrm{MeOH}, 10 \mu \mathrm{M})$. 


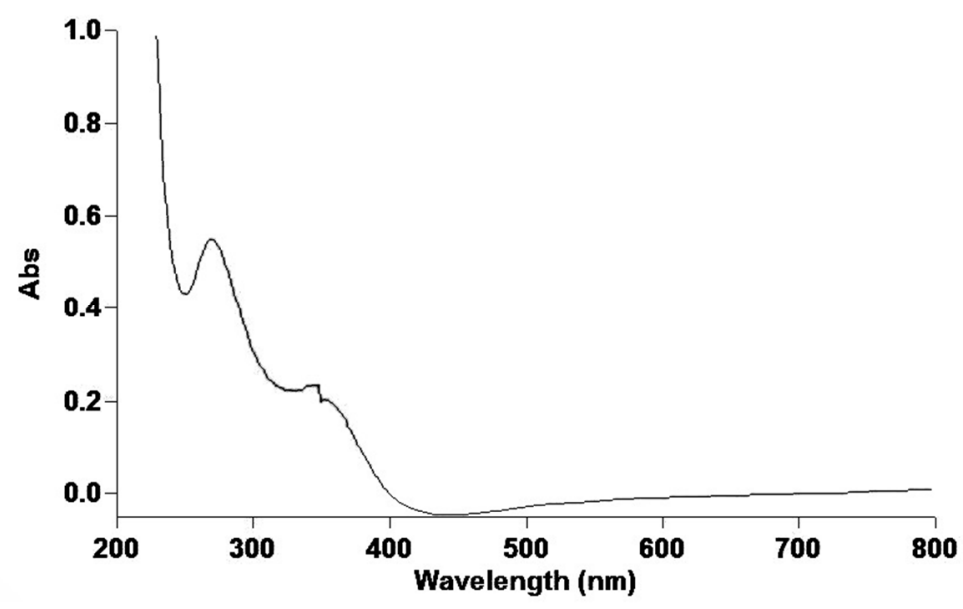

Figure S17. UV-vis absorption spectrum of 9 (MeCN, $10 \mu \mathrm{M})$.

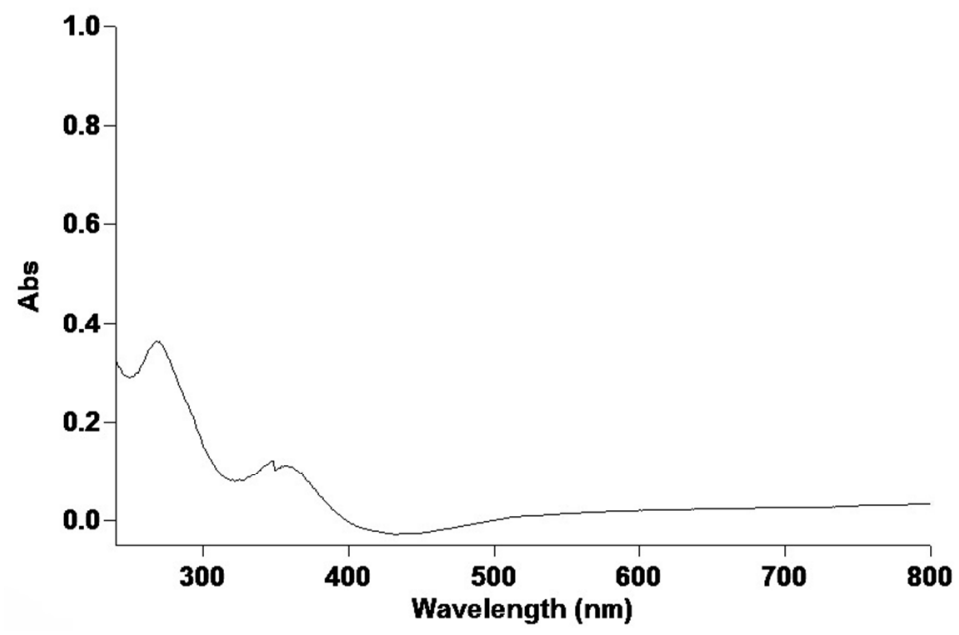

Figure S18. UV-vis absorption spectrum of $9(\mathrm{MeOH}, 10 \mu \mathrm{M})$.

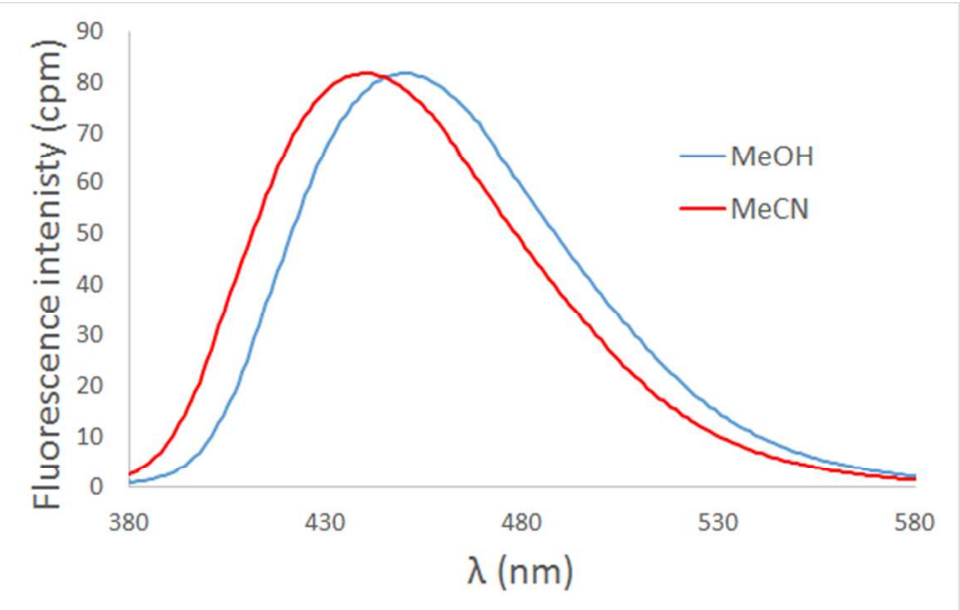

Figure S19. Fluorescence emission spectra of 2 in $\mathrm{MeCN}$ and $\mathrm{MeOH}, \lambda_{\text {ex }}=363 \mathrm{~nm},[2]=10 \mu \mathrm{M}$. 


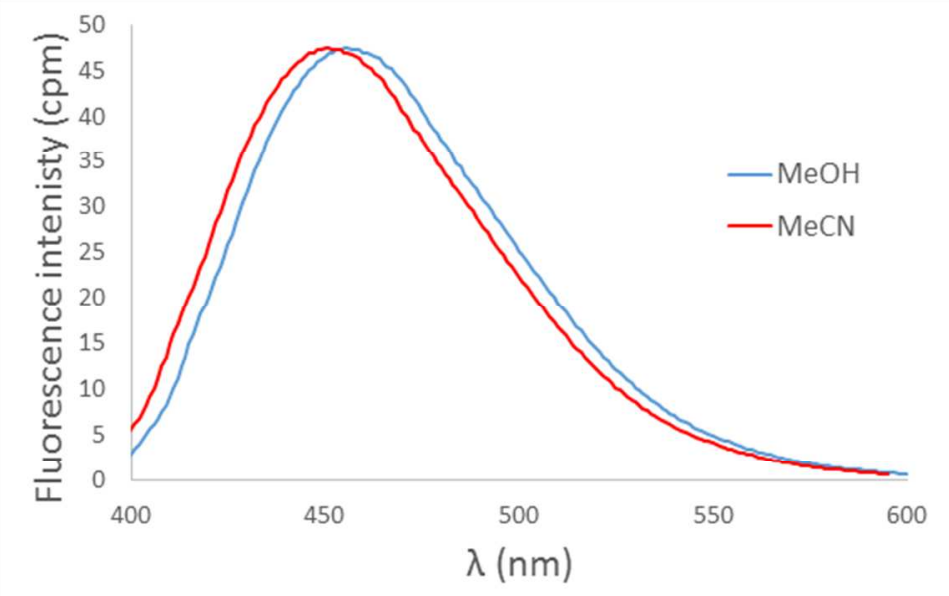

Figure S20. Fluorescence emission spectra of 4 in $\mathrm{MeCN}$ and $\mathrm{MeOH}, \lambda_{\text {ex }}=369 \mathrm{~nm},[4]=10 \mu \mathrm{M}$.

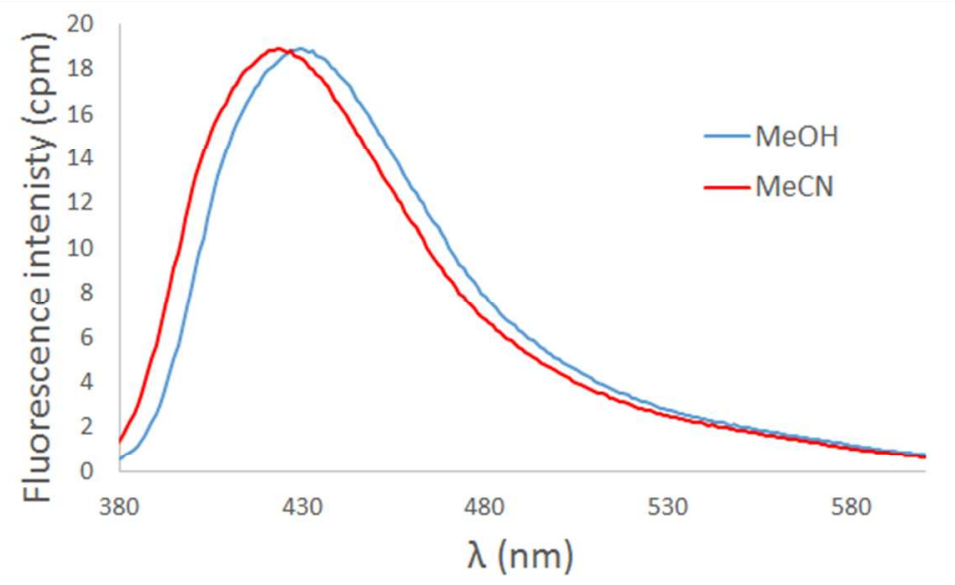

Figure S21. Fluorescence emission spectra of 6 in $\mathrm{MeCN}$ and $\mathrm{MeOH}, \lambda_{\mathrm{ex}}=354 \mathrm{~nm},[6]=10 \mu \mathrm{M}$.

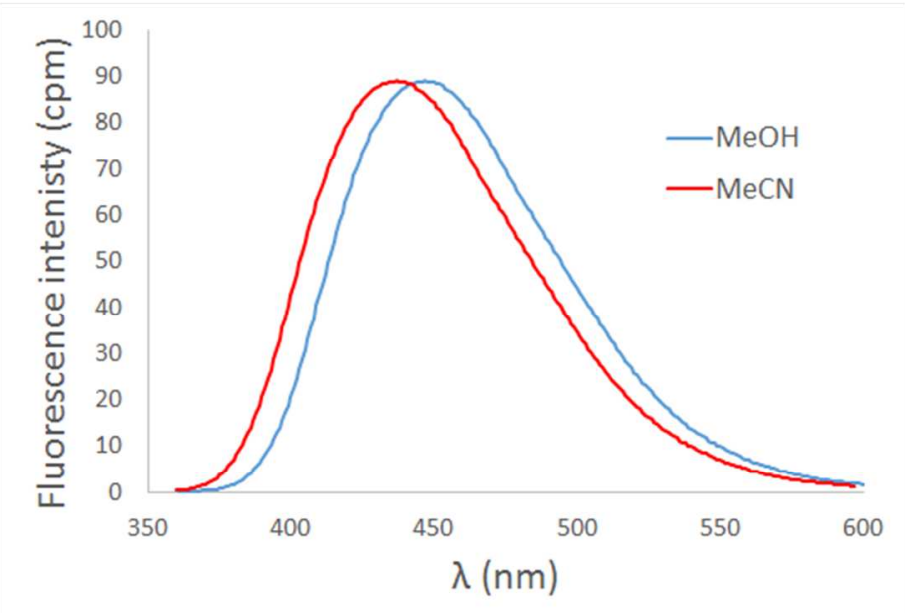

Figure S22. Fluorescence emission spectra of 9 in $\mathrm{MeCN}$ and $\mathrm{MeOH}, \lambda_{\mathrm{ex}}=354 \mathrm{~nm},[\mathbf{9}]=10 \mu \mathrm{M}$. 


\begin{tabular}{|c|c|c|}
\hline Cell Line & $\begin{array}{c}\text { Normalized Red:Green } \\
\text { Fluorescent Intensity }\end{array}$ & Standard Deviation \\
\hline A375 & 0.36 & 0.16 \\
\hline SK-Mel-3 & 0.53 & 0.07 \\
\hline NHFs & 0.30 & 0.10 \\
\hline
\end{tabular}

Table S1. Average FCCP values for the JC-1 assay. A375, SK-Mel-3, and NHF cells were incubated with 1 $\mu \mathrm{M}$ FCCP 30 minutes prior to JC-1 measurement by flow cytometry. 